\title{
Derecho y Política- Política y Derecho: cuando las políticas de ajuste impactan en las relaciones de familia ${ }^{1}$
}

\author{
Por Marisa Herrera ${ }^{2}$
}

\section{Palabras introductorias}

Se dice que el esfuerzo vale la pena; que no hay peor lucha que la que no se libra o la que se abandona; que no hay oportunidades únicas; todos estos dichos populares caben para el momento en el que escribo el presente trabajo cuya primera versión más reducida, formará parte de una obra colectiva que estamos elaborando un grupo de científicos argentinos comprometidos, ocupados y preocupados por la realidad actual. ¿Qué ha sucedido en los últimos tiempos con los Derechos Humanos como columna vertebral de todo el ordenamiento jurídico nacional y, en definitiva, de todos los subsistemas que integran una sociedad: la cultura, la educación, la salud, la justicia, la ciencia y tantas otras?

Colocar en jaque los Derechos Humanos ha implicado, en sustancia, un claro desorden o desorganización de ciertos cimientos que se creían sólidos, inamovibles e incuestionables. ¿Este es un artículo político? Seguro. ¿Un artículo jurídico? También. Sucede que lo jurídico es político o lo político es jurídico; ambos coquetean, interactúan, se mezclan, lo cual hace que la lectura del derecho sea más compleja y rica a la vez.

En esta oportunidad, quisiera destacar cómo las decisiones políticas adoptadas desde los últimos días de diciembre del 2015 hasta la actualidad afectan la aplicación del derecho en clave de derechos humanos, focalizándose en las relaciones de familia que desde hace tiempo se lo entiende constitucionalizado y convencionalizado tal como surge de los arts. 1 y 2 del Código Civil y Comercial (CCyC $)^{3}$. Es cierto que desde un

1 Una primera versión más reducida de este trabajo ha sido presentada para integrar una obra colectiva cuyo título tentativo es "Escritos urgentes sobre ciencia, educación y justicia. Reflexiones frente al avance neoliberal", elaborada por los integrantes del Grupo Ciencia y Técnica Argentina (Adrián Paenza; Alberto Kornblihtt; Ana Franchi; Andrea Gamarnik; Andrés Kreiner; Carolina Mera; Daniel Filmus; Diego Hurtado; Diego Tatian; Dora Barrancos; Eduardo Dvorkin; Emmanuel Alvarez Agis; Federico Robledo; Felix Requejo; Fernanda Beigel; Graciela Morgade; Hugo Aimar; Jorge Aliaga; Jorge Geffner; José Paruelo; Juan Pablo Paz; Luis Alberto Quevedo; Marcelo Ruiz; Marisa Herrera; Mirta Susana Iriondo; Noé Jitrik; Osvaldo Uchitel; Pablo Nuñez; Raquel Chan; Roberto Salvarezza; Rolando González-José; Sandra Carli) y publicada por la editorial Punto de Encuentro en alianza con la Universidad Nacional de Avellaneda.

2 Investigadora Independiente, CONICET. Profesora, Facultad de Derecho UBA y Facultad de Economía y Ciencias Jurídicas de la UNLP. Integrante del Grupo Ciencia y Técnica Argentina.

3 Como se explicita en los Fundamentos que acompañaron al entonces Anteproyecto de Reforma y Unificación del Código Civil y Comercial, antecedente directo del texto civil vigente desde el 01/08/2015: "La mayoría de los códigos existentes se basan en una división tajante entre el derecho público y privado. El 
primer acercamiento, se podría aseverar que los principales ámbitos afectados habrían sido el derecho penal y el derecho laboral, fácil y sintéticamente comprobada en la elocuente frase "este modelo no cierra sin represión"; entendida esta última noción en su acepción primaria, es decir, como afección a la integridad física; y también como restricción al derecho a la dignidad a través del trabajo como factor básico de inclusión social. Sin embargo, desde una perspectiva más profunda, no se puede dejar de observar cómo las relaciones de familia también habrían sufrido un claro retroceso producto de la degradación del tejido social a raíz de la reconceptualización del rol del Estado en el que los Derechos Humanos en acto, no tienen un lugar de relevancia sino sólo en los papeles a través de un logo como resabio de la denominación que ya traía algún Ministerio ${ }^{4}$.

Varios debates que se entendían sorteados vuelven a la escena jurídica de un modo un tanto perverso, es decir, mediante propuestas demagógicas y con poco espacio para intercambios verdaderamente plurales. El proyecto presentado por el Poder Ejecutivo en junio de 2017 de "libertad religiosa" que pretende cambiar el paradigma constitucional de neutralidad estatal y la consecuente defensa por un Estado Laico, hacia uno que defienda la objeción de conciencia institucional para, en definitiva, dar por tierra una gran cantidad de derechos conquistados, como todos los que involucran a grupos sistemáticamente discriminados, como las personas LGBTI o las mujeres y el acceso a la interrupción del embarazo en los casos permitidos por la ley de conformidad con lo interpretación de la entonces Corte Federal en el resonado caso FAL ${ }^{6}$, cuando también

Anteproyecto, en cambio, toma muy en cuenta los tratados en general, en particular los de Derechos Humanos, y los derechos reconocidos en todo el bloque de constitucionalidad. En este aspecto innova profundamente al receptar la constitucionalización del derecho privado, y establece una comunidad de principios entre la Constitución, el derecho público y el derecho privado, ampliamente reclamada por la mayoría de la doctrina jurídica argentina (...) Puede afirmarse que existe una reconstrucción de la coherencia del sistema de derechos humanos con el derecho privado". Se trata, ni más ni menos, de un modo diferente de razonar y pensar el derecho civil y comercial fundado más en la ponderación que en la subsunción como método tradicional de pensar el Derecho, siempre teniéndose en cuenta los derechos humanos comprometidos.

4 iAcaso la propuesta para integrar la Comisión Interamericana de Derechos Humanos del abogado defensor de represores durante la última dictadura cívico militar, Carlos Horacio de Casas por parte del Estado Argentino que fuera rechazada por la OEA, no ha sido una prueba elocuente, entre tantas otras?

5 Proyecto de ley 0010/PE/2017 presentado el 12/06/2017. En especial, la preocupación máxima gira en torno al texto de los arts. 7 y 8 . El art. 7 se refiere a la objeción de conciencia institucional y lo hace de una manera extremadamente amplia al sostenerse: 1) que "La buena fe del objetor se presume por la disposición a cumplir una prestación alternativa razonable, o por la existencia de una norma obligatoria expresa impuesta por la entidad religiosa a la que pertenezca de modo comprobado el objetor"; 2) que "El objetor no podrá recibir sanción ni sufrir discriminación alguna por el ejercicio de su derecho” y 3) que la objeción de conciencia puede ser ejercido en una gran cantidad de ámbitos como: "prestación del servicio militar, cumplimiento de tareas profesionales en el ámbito sanitario, sometimiento a tratamientos médicos, homenaje activo a símbolos patrios, juramentos, actividad laboral o escolar en días de fiesta o descanso religioso; ello sin perjuicio de lo establecido en el artículo $8^{\circ}$ de la presente Ley en materia de adecuación razonable en los ámbitos pertinentes"; articulado este último que se refiere a la "adecuación razonable" de un supuesto derecho como lo es la objeción de conciencia, que de por sí tiene límites indefinidos o indeterminados; por lo cual es proclive a habilitar y justificar el incumplimiento de una gran cantidad de obligaciones jurídicas que repercutirían en flagrantes violaciones a los derechos humanos de las mujeres así como de toda persona que no profese culto alguno.

6 Corte Suprema de Justicia de la Nación, 13/03/2012, “F., A.L. s/Medida autosatisfactiva”, SJA 2012/05/23. 3 Cita Online: AP/JUR/55/2012. 
la máxima instancia judicial del país se movía en aguas guiadas por los Derechos Humanos. Como bien se asevera en una nota de repudio elaborada por la Alianza de Abogadas/os por los Derechos Humanos de las Mujeres ${ }^{7}$, espacio que reúne a más de 200 abogadas/os de todo el país, dirigida a los diputados y diputadas integrantes de las comisiones Relaciones Exteriores y Culto; Legislación Penal y Presupuesto y Hacienda por ser las que deben tratarlo:

Los conceptos de Estado de Derecho y laicidad estatal o estado laico están entrelazados y uno no es posible sin el otro. El desarrollo, avances y consolidación de la obligada perspectiva de Derechos Humanos a la que estamos obligadas/os en virtud de nuestro texto constitucional, encuentra entre sus cimientos la defensa por la neutralidad religiosa. De este modo, el Estado no puede argumentando defender una falsa 'libertad religiosa', imponer determinadas preferencias y privilegios a ciertos credos, obligando a las personas y comunidades a seguir principios y reglas propias de religiones a las que no adhieren ni practican. Precisamente, la laicidad impone un deber de neutralidad estatal, por la cual el Estado no impone o promueve determinados cultos"; nota que culmina expresando: "Por estas razones basadas en la justicia social y como personas y colectivos comprometidos/as con la defensa de los derechos humanos en un ámbito plural y democrático que hemos forjado en nuestro país, solicitamos a las y los diputados/as de la Nación integrantes de las comisiones mencionadas, rechazar de plano la propuesta enviada por el Poder Ejecutivo Nacional, en virtud de la afectación directa y cabal a los derechos fundamentales que tal iniciativa implica para amplias franjas de la población argentina, en especial, para las mujeres, niñas/os y adolescentes, así como toda persona que no adhiera a culto alguno (Ciencia y Técnica Argentina, 2017).

En esta misma lógica crítica del contexto político y su impacto directo en la actuación de la Corte Federal se podría citar el retroceso que significa colocar en debate la legislación salteña en lo relativo a la educación religiosa en las escuelas públicas. ¿Acaso era un tema para abrir a la presentación de amicus curiae ${ }^{8}$ y a audiencias públicas o,

7 Quien firma este artículo integra esta Alianza.

8 Merecen destacarse dos amicus curiae presentados. Uno pertenece al profesor Laferriere, muy cercano al Arzobispado y acérrimo opositor a todas las leyes de ampliación de derechos en el campo de las relaciones de familia como la ley de matrimonio igualitario, identidad de género, muerte digna, cobertura en técnicas de reproducción asistida y como era de presumir, la regulación del Libro Segundo del CCyC. Este autor afirma:"es mi intención poder aportar reflexiones que contribuyan a la decisión de la causa en el sentido de sostener la constitucionalidad de la Constitución de Salta, de su legislación y de sus prácticas, de modo que se asegure el derecho de los padres a educar a sus hijos conforme sus convicciones, lo que incluye la posibilidad de que reciban educación religiosa en las escuelas públicas". En esta línea, este autor puntualiza que "la mención a Dios en el preámbulo y el explicito texto del artículo 2 de la Constitución Nacional, señalan una hermenéutica constitucional compatible plenamente con el reconocimiento de Dios y su lugar en la vida y las prácticas de la República Argentina”. Asimismo, entiende que "privar a los niños de la enseñanza religiosa conduce al analfabetismo porque, sin conocer nada sobre las religiones, le resultará muy difícil a un niño entender y disfrutar muchas obras de arte, y tantas referencias, directas e indirectas, que se han a las Sagradas Escrituras y a las 
directamente, dictar sentencia y poner fin a un debate ya sorteado hace tantísimos años? ¿Sobre la base de qué vara la máxima instancia judicial federal abre o cierra debates judiciales que presume son de interés social? En esta misma línea, cabría preguntarse por qué el caso Muiña (Corte Suprema de Justicia de la Nación, 2017) no obtuvo el mismo tratamiento que el caso Castillo (Corte de Justicia de la Provincia de Salta, 2014) proveniente de una Corte provincial como la salteña, ancestralmente muy conservadora como la provincia en sí. Como es sabido, texto y contexto se retroalimentan y en esta línea, se podría aseverar que cada lugar tiene la corte que se merece; es decir, que el poder político decidió tener.

Lo que aquí se pretende visualizar es la interacción entre política y derecho a través de situaciones concretas que protagoniza el derecho civil, el que tampoco ha podido ni puede escapar de los embates de la política. ¿Acaso es casualidad la intención del Ministerio de Justicia de la Nación de modificar el CCyC a sólo dos años de su puesta en vigencia mediante la conformación de un grupo de trabajo integrado por juristas de reconocida trayectoria en grandes estudios jurídicos, académicos cercanos al poder eclesiástico y profesores conocidos por sus posturas conservadoras y, como era de presumir, en su gran mayoría varones?

Sí, es cierto, se trata de un artículo un tanto diferente a tantísimos otros. A mi entender, en los tiempos que corren, se necesita redoblar los esfuerzos por desenmascarar ciertos principios tan falaces como perversos que han rodeado al Derecho: que es "apolítico", insípido, inodoro e incoloro como el agua. Todo lo contrario.

En definitiva, este artículo pretende colaborar a la necesaria deconstrucción del derecho, en el que es básico mostrar todas sus facetas; lo que dice, pero en especial, lo que silencia; lo que muestra, pero en particular, lo que esconde; lo que aún muchos académicos del derecho le tienen terror: aceptar que "las facultades de Derecho son lugares intensamente políticos" como afirma de manera elocuente y sabia el profesor norteamericano Duncan Kennedy (2004: 117).

\section{Cuando Ajuste, Estado y Derecho se contraponen}

De manera harto sintética, es dable afirmar que las políticas neoliberales ${ }^{9}$ se caracterizan, entre otras cosas, por revalorizar, endiosar y dejar ser y hacer a las grandes

tradiciones religiosas en la vida social”. El otro amicus corresponde al ex ministro de la Corte Federal, Rodolfo Barra, cuya afinidad con la Iglesia Católica es conocida. Ambos defienden, como era fácil de presumir, la obligación de la educación religiosa en las escuelas públicas salteñas.

9 Que algunos autores califican de un neoliberalismo "periférico" como lo asevera Hurtado al destacar que "A diferencia del neoliberalismo de países desarrollados como EE.UU., Gran Bretaña o Alemania -los 'países normales' en el ideal ahistórico macrista-, que sostienen con inversión pública masiva una intensa actividad científico-tecnológica como motor de la competitividad de sus economías, el neoliberalismo periférico de la alianza Cambiemos, en asociación con los grupos económicos empresarios de naturaleza financiera y oligopólica en sectores de procesamiento de materias primas, necesita elevar la desocupación a un 15\% y bajar los "costos laborales" a través de una ley de 'flexibilización laboral'. Es decir, la caída del salario real, el deterioro de las condiciones laborales y una menor cobertura de seguridad social, indemnizaciones, vacaciones, etc., paradójicamente aumentarían la competitividad de las empresas" (Hurtado, Diego, "Neoliberalismo periférico y 
corporaciones transnacionales; a la par o ello es condición necesaria y suficiente para forjar un fuerte repliegue del Estado en su rol de garante último y esencial de los derechos humanos de todxs los cuidadanxs ${ }^{10}$.

Siguiéndose a Cantamutto y Schorr, investigadores del CONICET y miembros de la Sociedad de Economía Crítica al preguntársele acerca de cuál es el modelo económico del gobierno de la Alianza Cambiemos, responden que

Los datos oficiales permiten identificar un rumbo claro aunque no exento de contradicciones. No deben confundirse los titubeos y los pedidos de disculpas con una falta de orientación; ocurre que el rumbo elegido encuentra trabas sociales, que, aunque le hacen modificar el ritmo, no consiguen cambiar la dirección (...) Los ejes centrales de este rumbo son la apertura y la desregulación de la economía, que producen un severo ajuste social. No se trata del abandono del rol regulatorio del Estado, sino de su orientación en un sentido específico a favor de los intereses sectoriales bien concretos (Cantamutto, 2017:6).

He aquí entonces dos reflexiones a modo de disparadores.

La primera, contrariamente a lo que exponen los autores, sí sería pertinente hablar de "abandono del rol regulatorio del Estado" en el campo de los derechos humanos, en especial, de los derechos civiles y sociales porque, precisamente, su ampliación impactaría de modo negativo en intereses sectoriales bien concretos; véase como ejemplo lo que está aconteciendo en el campo del derecho a la salud ${ }^{11}$, en el que la mayor cobertura es vista como un "gasto" y de allí, toda la reestructuración profunda en diferentes niveles -tanto institucional como de recursos humanos- en la atención de la salud mental para estar a tono con la ley nacional de salud mental (ley 26.657) por imperio y fuerza de la Convención de los Derechos de las Personas con Discapacidad que a fines del 2014 adquirió jerarquía constitucional, y fue reafirmada en el nuevo Código Civil y Comercial; observándose un frustrante desarme de toda política de "desmanicomialización" a tono con el modelo social de la discapacidad pensada en la persona en su individualidad e identidad. Aquí la falta de regulación o cambio en la orientación regulatoria del Estado es sinónimo de darle la espalda a un grupo social claramente, vulnerable.

La segunda, se vincula a las "trabas sociales" a las que se alude. ¿En qué medida las limitaciones, frenos y contraofensivas sociales no son consecuencia de los derechos

'sociedad de des conocimiento'", disponible en:http://www.oetec.org/nota.php?id=2370\&area=1, compulsado el 08/05/2017).

10 Modificar la redacción en términos de igualdad y no discriminación dejándose de lado el masculino que ha sido el que ha guiado y guía la escritura formal como informal, ha sido también uno de los tantos debates generados durante la época de extensión o ampliación de derechos en el que la perspectiva de género ha ocupado un lugar protagónico en ese entonces.

11 Se recomienda la lectura ácida de las múltiples entrevistas y artículos en el primer número de la Revista Soberanía Sanitaria, nro. 1, junio 2017, disponible en:http://revistasoberaniasanitaria.com.ar/, compulsado el 25/07/2017. 
conquistados durante el kirchnerismo y reflejo de una transformación cultural en sentido amplio -también cabe para la ciencia y tecnología- "inconclusa"?

Repliegue del Estado y activismo social en los campos más sensibles o de cara a las personas (¿el tan vapuleado "populismo"?) constituyen la fricción que cuan nudo conductor, motoriza el presente artículo focalizado en los retrocesos y ciertas perplejidades en el cruce ¿perverso? entre neoliberalismo y derechos humanos civiles y sociales, destacándose que caracterizar de "humanos" a los derechos civiles y sociales puede ser una redundancia, pero en las épocas que corren, tal reiteración forma parte de la no centralidad de los derechos humanos en la agenda pública de hoy.

Es sabido que el Estado se encuentra integrado por tres poderes, los cuáles se encuentran íntimamente entrelazados entre sí; en el que la decisión de uno impacta de manera directa en los demás a través de diferentes tipos de vínculos, más o menos visibles y más o menos aceptables, desde la media de lo políticamente correcto ${ }^{12}$. En este contexto, la degradación del lugar del Estado se la puede analizar a la luz de la "bipolaridad" observada en el comportamiento del Poder Legislativo. Por un lado, un fuerte desarrollo legislativo en contra de los intereses de las personas con una colaboración activa por parte de sectores que se podrían sintetizar bajo la noción ya asimilada de "opo-oficialistas" y por el otro, una agobiante baja en la calidad institucional medida sobre la base del grado y tenor de los proyectos de ley que se presentan y debaten en la "Casa del pueblo".

¿Cómo avanzar en proyectos que profundicen la perspectiva de Derechos Humanos en un contexto en el que el corazón de esta mirada sintetizada bajo las palabras de "Memoria, Verdad y Justicia" se encuentra en franco retroceso, al punto de volver a colocar en la escena mediática la nefasta y perversa "Teoría de los dos demonios", o en tela de juicio el número 30.000, con todo lo que ello significa, avalada por la máxima instancia judicial del país ${ }^{13}$ y con la bendición de la Iglesia Católica?

¿Cómo poder siquiera, proponer ideas que puedan alcanzar formato de ley en diferentes cuestiones pendientes sobre determinados colectivos sociales sistemáticamente invisibilizados y discriminados que encontraron su espacio en la agenda pública de la denominada "docena ganada" (Herrera, 2016: 289-317), cuando el eje está puesto en la noción de "seguridad" y la consecuente mayor represión estatal? En este sentido, puestas en escena como la baja de la edad de punibilidad y la consecuente actualización de debates espasmódicos y demagógicos en torno al lema que se defiende de "No a la baja"; o en el mismo sentido - también a raíz de un caso doloroso- se logró la sanción en fecha 5/07/2017de una ley que modifica el régimen de ejecución de penas para los autores de delitos violentos, es decir, que los condenados por homicidios, robos

12 Como ejemplo, el avance contra la destitución de juicios solicitado de manera explícita por quien encabeza el Poder Ejecutivo, véase: "Desde el Pro piden juicio político para el juez Rafecas”, Parlamentario, 22/06/2016, disponible en:http://www.parlamentario.com/noticia-92869.html y "Piden juicio político a dos jueces que avalaron el aumento bancario", Perfil, 21/02/2017, disponible en:http://www.perfil.com/politica/trabajo-pidio-eljuicio-politico-de-los-jueces-que-avalaron-la-paritaria-bancaria.phtml, compulsados el 03/05/2017.

13 Ver Corte Suprema de Justicia de la Nación, 03/05/2017, "Recurso de hecho deducido por la defensa de Luis Muiña en la causa Bignone, Reynaldo Benito Antonio y otro si recurso extraordinario", op.cit. 
con armas de fuego y violaciones dejarían de gozar del beneficio de las salidas transitorias y la libertad condicional; son hechos políticos -en definitiva, culturales desde una idea más compleja y profunda de este término- que giran sobre un interrogante clave: “¿Más cárcel y qué?”, colocándose en tela de juicio

desde la perspectiva de género, vemos varios problemas. Se hace evidente que el proyecto se presenta para dar una respuesta rápida ante las múltiples demandas que surgieron a partir del femicidio de Micaela, cometido por un hombre que cumplía una condena por violación y que estaba en libertad condicional, por lo que es una respuesta aislada y acotada ante una problemática que excede el marco punitivista, aunque no lo exime y que requiere un abordaje mucho más integral. Insistir con que el derecho penal es la única alternativa para enfrentar la violencia contra las mujeres, niñas y adolescentes es un error. El derecho penal sólo se hace efectivo cuando la violencia se ha manifestado sobre nuestros cuerpos. Un abordaje más eficiente sería considerarlo como una herramienta con la que contamos las mujeres, en el marco de muchas otras políticas públicas, que deberían existir para prevenir y erradicar la violencia de género, así como dispositivos de acción que resuelvan los problemas materiales de las mujeres que atraviesan situaciones de violencia y que les brinden alternativas y opciones. A su vez, se hace urgente que el Poder Judicial incluya la perspectiva de género y que se presenten iniciativas de paridad para los altos cargos dentro del Judicial, así como capacitaciones de calidad e importancia sobre la problemática. Actualmente el Poder Judicial trabaja con nula percepción del riesgo en el que nos encontramos las mujeres y suele incurrir en revictimizaciones basadas en estereotipos de género que poca relación tienen con la realidad (...) En un sistema patriarcal donde el machismo es ley, queda claro que quienes violan y matan a las mujeres no están incumpliendo las leyes, por el contrario, las están enunciado y exponiendo. Por eso, en lugar de destinar recursos a endurecer las penas, el Estado debería, por empezar, abocarse a impulsar la paridad de género en las listas legislativas; debido a que resulta casi cínico que las leyes destinadas a defender la vida, los derechos, las libertades y la integridad de las mujeres, se debatan en un espacio integrado en su mayoría por varones sin perspectiva feminista (59\% 29 mujeres y 43 varones) y a diseñar políticas públicas y de capacitación desde todos los espacios, con el fin de que no tengamos que morir para que se exija "justicia" en nuestro nombre" (Comunicado de la Red de Mujeres, 2017).

Es así que con una baja expectativa pero un claro compromiso social, varias activistas, académicas e investigadoras sociales elaboraron un proyecto de ley, la "Ley Micaela"14

14 1776-D-2017 presentado por el bloque del FPV. 
que, defendiendo una línea preventiva y no represiva, dispone en su art. 1: "Establécese la capacitación obligatoria en la temática de género y violencia contra las mujeres, para todas las personas que se desempeñen en la función pública en todos sus niveles y jerarquias.

¿Será entonces que las políticas neoliberales bregan más por salidas superficiales y efectistas en términos electorales más que por soluciones reales, en las que se utiliza a colectivos vulnerables como los adolescentes y las mujeres como excusa para lograr un mayor "orden", es decir, endurecer las penas?

Tampoco se ha podido avanzar en conflictivas que pretendieron ser resueltas en una ley especial como aconteció con la cuestión del embrión no implantado o in vitro que tanta polémica generó durante el debate del nuevo Código Civil y Comercial en su art. 19 dedicado a establecer cuándo comienza la existencia de la persona humana. Al respecto, cabe recordar que este articulado, en su versión original, mantenía la redacción del Código velezano fundado en la noción de concepción siendo este el término que utiliza la Corte Americana de Derechos Humanos en su art. 4.1. Ahora bien, en el caso de técnicas de reproducción humana asistida se aclaraba que la concepción se producía recién con la implantación del embrión en la persona y, por lo tanto, el embrión no implantado no podía ser considerado persona. En otras palabras, la necesidad de diferenciar "fecundación" que es la unión entre óvulo y esperma, de "concepción" que acontece cuando el embrión anida y comienza a desarrollarse dentro del cuerpo de la persona. Esta propuesta fue quitada por presión de la Iglesia Católica y como solución de consenso, se decidió que una ley especial regulara todo lo relativo al embrión $^{15}$. Así se hizo en un proyecto de ley (581 y 4058-D-14, OD 1003) que fue aprobado en la Cámara de Diputados el 12/11/2014 en el que se pretendía cerrar el círculo de la regulación de un tema que parecería ser sensible por los aspectos éticos que comprometen las técnicas de reproducción asistida. ¿En qué sentido se regulaba la cuestión del embrión, en especial, lo relativo a su destino? De manera amplia, es decir, permitiéndose todos los destinos posibles, esto es: 1) crioprservación para posteriores tratamientos de la pareja o persona; 2) donación para terceros, 3) donación para investigación y 4) decidir el cese de la criopreservación o sea, su descarte por elección libre de las personas que se someten a estas prácticas y por alguna razón no quieren hacer uso de los demás destinos. ¿Qué sucedió con ese proyecto en la Cámara de Senadores? Por pedido de quienes lo impulsaban -un grupo de investigadores, organizaciones de pacientes, médicos y demás profesionales que trabajan en la temáticaen una reunión mantenida en Casa de Gobierno, decidieron que el proyecto no sea tratado y, por lo tanto, que pierda estado parlamentario. ¿Cuál fue la razón para que los propios impulsores del proyecto de ley breguen por su caída? La propuesta gubernamental de que una organización de la sociedad civil del Opus Dei se hiciera

15 Para profundizar esta cuestión que no pudo ser abordada a la altura de las circunstancias tampoco en la gestión anterior ver entre otros: Herrera, Marisa; Kemelmajer de Carlucci, Aída y Lamm, Eleonora, "Hacia la ley especial de reproducción asistida. Cuando la razón prima” en LA LEY 27/11/2014, 1 Cita online: AR/DOC/4369/2014; Herrera, Marisa; Kemelmajer de Carlucci, Aída y Lamm, Eleonora, "El embrión no implantado. El Proyecto de Código y su total consonancia con la CIDH” en LA LEY 28/12/2012, 1 Cita Online: AR/DOC/6204/2012 y Herrera, Marisa; Kemelmajer de Carlucci, Aída y Lamm, Eleonora "El embrión no implantado - Proyecto de Código unificado. Coincidencia de la solución con la de los países de tradición común" en LA LEY 10/07/2012 , 1 Cita Online: AR/DOC/3340/2012. 
cargo de los embriones existentes en el país. Nunca se había tenido una respuesta estatal de este tenor y ante este contexto, se apeló a un dicho que suele ser escuchado en los pasillos de ámbitos jurídicos: "es mejor no tener ley, que tener una mala ley". ¿Acaso si los embriones in vitro según el gobierno son persona, no deberían hacerse cargo ellos de estas "personitas" como garante último de los derechos humanos de los ciudadanos y no una organización no gubernamental? El conocido y en su momento bien criticado "onegeísmo", pareciera ser otro principio clave del actual neoliberalismo periférico.

Es así como todo el esfuerzo y consenso logrado durante la gestión anterior en alcanzaren la Cámara de Diputados la aprobación de una normativa laica en un tema como la reproducción asistida en el que la religión suele adquirir un rol central o determinante, se diluyó casi de manera instantánea después de una reunión en el hábitat cotidiano donde transcurre y discurre el Poder Ejecutivo. En fecha 02/03/2017 se presentó un nuevo proyecto, igual de progresista que el anterior en lo que respecta al embrión no implantado y más extenso al abarcar otras cuestiones que en su momento no pudieron ser consensuadas. ¿Este nuevo proyecto se convertirá en ley durante esta gestión? La respuesta negativa se impone; su presentación sólo responde a la necesidad y el compromiso de seguir colocando en la agenda legislativa voces progresistas que se animen a dar el debate por un ordenamiento jurídico laico, en la misma sintonía del camino que se comenzó a gestar y construir hace algunos años cuando se sancionaron leyes absolutamente rupturistas que se animaron a poner en crisis "lo natural" o "lo dado", es decir, nociones ancestrales como heterosexualidad, patriarcalismo, y potestad; leyes destinadas a una determinada clase social: media, blanca y educada.

Como bien lo asevera Alicia Ruiz en un artículo titulado "Mujeres y Justicia" en el que critica de manera acertada la noción "Todos" que suelen utilizar las leyes:

Entre esos "todos" no están los pobres, ni los inmigrantes, ni los desocupados, ni aquellos a los que por su color de piel, por su creencias religiosas, por su opción sexual, por su ideología política, por su adicción, por estar acusados de un delito o por haber sido condenados, por estar en prisión o por haber salido de ella, por estar enfermos sin atención o por haber sido aislados en una institución médica, por ser un niño o un adolescente con "problemas de conducta o "en situación de calle", etc. La lista sería interminable; en ella están los "desechables" (según Balibar), los excluidos, los negados, los perseguidos a los que justamente el derecho debería amparar. El horizonte luminoso de la igualdad es apenas perceptible. Una ilusión que sostiene malamente el imaginario de la modernidad frente a un mundo oscuro y opaco, habitado por individuos sin identidad ni reconocimiento, a los que se procura invisibilizar, desconocer y olvidar. Seres vulnerables de "vulnerabilidad extrema" hacia los cuales solo se dirigen, casi siempre, y en el mejor de los casos, miradas indiferentes (encubiertas a veces de un manto de piedad definitivamente hipócrita) o disfrazadas bajo alguna forma de "asistencialismo (Ruiz, 2017 en línea). 
Precisamente, una de las grandes conquistas en materia de derechos civiles y sociales en el sentido más profundo y amplio del término "social" que incluyen los derechos civiles y políticos, ha sido desenmascarar esa idea impersonal, escéptica e hipócrita de presumir que somos todos iguales y que ese "Todos" nos iguala, sin atreverse a mirar las desigualdades y actuar en consecuencia. Accionar que, en la gran mayoría de las veces, involucra un rol activo por parte del Estado desde sus tres poderes, el legislativo al reconocer las diferentes identidades, el judicial al intervenir de manera supletoria ante cualquier incumplimiento y el ejecutivo, el más comprometido a través de la implementación de diferentes políticas públicas.

En este contexto adverso, cabe preguntarse cuál es el rol de las ciencias sociales. ¿Acaso el impulso y expansión de la investigación social no se relaciona de manera directa con el contexto sociopolítico en el cuál se desarrollan? En esta línea argumental, es entendible que se vuelva a una falsa disyuntiva entre ciencias duras y ciencias blandas, o de una manera más mediática, entre ciencia "útil" e "inútil" como lo expusieron a modo de diálogo forzado dos medios periodístico del establishment, cuando aseveraron que "El Conicet decidió darles prioridad a los investigadores 'más útiles' para el país" (Sigal, 2017) y al poco tiempo, otro le respondió preguntándose " ¿Ciencia 'inútil?' Por qué la investigación básica, humana y social es estratégica” (Kukso, 2017). ¿Cómo caímos de manera regresiva, a esta vieja y perimida disyuntiva? Al igual que "caímos de la educación pública”, estas caídas forman parte, marcan y delinean una determinada época.

Esto lo expone de manera precisa Carolina Mera quien al preguntarle sobre

¿Para qué sirven las ciencias sociales? ¿Por qué, todavía en 2017, hay que justificar la importancia de sus contribuciones en las dinámicas de la sociedad? ¿Por qué los grupos hegemónicos construyen campañas de desprestigio que las ubican como blanco principal? ¿De qué manera su enfoque contextual, histórico y desmitificador incomoda al poder? Y, por otra parte, ¿qué lugar ocupan las mujeres en el sistema científico? ¿Es cierto que si bien hay mejores posibilidades, los puestos de jerarquía se reservan para los hombres?".Se responde con absoluta convicción que partiéndose de la idea de que "Pertenecemos a un capitalismo brutalmente excluyente y productor de desigualdades en todos los planos. Una realidad que constantemente interpela a las ciencias sociales y las invita a producir conocimientos para modificar el presente" es que "la reflexión científica, crítica y comprometida incomoda al poder siempre que obliga a nuestros representantes a diseñar estrategias que nada tienen que ver con las respuestas inmediatas. Justamente los grupos económicos concentrados son los responsables de promover la seguridad vía la represión y el control, la medicalización, la estigmatización de los migrantes como "chivos expiatorios" en momentos de crisis, recesión y ajuste. De este modo nadie puede decir que las ciencias sociales no sirven, por el contrario, son muy útiles para pensar un mundo desde una 
perspectiva que al sistema capitalista, neoliberal y hegemónico no le conviene (Mera, 2017). ${ }^{16}$

Esto mismo habría acontecido -en buena hora y a lo mejor con menor fuerza que en otros ámbitos sociales- en el mundo jurídico a la luz de la bandera de los Derechos Humanos.

\section{Hacia una agenda de resistencia propositiva: los logros como fortaleza y escudo}

Una buena sobredosis de producción legislativa han marcado a los gobiernos kirchneristas; solo por hacer un brevísimo paneo en orden ascendente: la ley 25.871 de Migraciones; la ley 25.778 que le otorga jerarquía constitucional a la Convención sobre Imprescriptibilidad de los Crímenes de Guerra y de los Crímenes de Lesa Humanidad; la ley 25.929 que obliga a las obras sociales y prepagas a cubrir determinadas prestaciones por embarazo y derivado del parto y post parto; la ley 26.061 de Protección Integral de Derechos de Niños, Niñas y Adolescentes; la ley 26.130 que reconoce el derecho a acceder a la ligadura de trompas y vasectomía de derechos de la relación médico paciente; ley 26.150 que crea el Programa de Educación Sexual Integral; la ley 26.165 de "Reconocimiento y Protección al refugiado"; la ley 26.206 de Educación Nacional; la ley 26.227 que crea el Consejo Federal de la Juventud; la ley 26.298 que aprueba la Convención Internacional para la Protección de las Personas contra las Desapariciones Forzadas; la ley 26.390 que prohíbe el trabajo infantil y protege el trabajo adolescente; la ley 26.485 de Protección Integral para prevenir, sancionar y erradicar la violencia contra las mujeres en los ámbitos en que se desarrollen sus relaciones interpersonales; la ley 26.522 de Servicios de Comunicación Audiovisual; la ley 26.529 de "Derechos de los pacientes en su relación con los profesionales e instituciones de la salud"; la ley 26.618 conocida como "ley de matrimonio igualitario"; la citada ley 26.657 de "Derecho a la protección de la salud mental"; la ley 26.682 que regula el régimen jurídico de la medicina prepaga; la ley 26.742 conocida como "ley de muerte digna"; la ley 26.743 de identidad de género;la ley 26.776 que amplía el derecho al voto al permitir de manera optativa a los adolescentes desde los 16 años; la ley 26.842 para la "prevención y Sanción de la Trata de Personas y Asistencia a sus víctimas"; y la ley 26.862 de acceso integral a las técnicas de reproducción asistida ${ }^{17}$. Aquí sólo se citan una veintena de cuerpos normativos que permiten advertir de manera contundente, el tenor de los debates que ellos han generado y en especial, la ampliación y profundización de los derechos humanos en sus diferentes facetas y vertientes, sin poder dejar de lado lo que ha implicado para la vida cotidiana de las personas en un lapso nada desdeñable -desde el nacimiento o incluso antes, hasta la muerte-como lo es el

16 Reportaje a Carolina Mera en https://www.pagina12.com.ar/52444-la-reflexion-cientifica-critica-incomodaal-poder compulsada el 26/07/2017.

17 Para tener un panorama más amplio sobre las conquistas legales adquiridas durante el gobierno de Néstor y CFK se recomienda compulsar: 10 años de Políticas Públicas para la Inclusión y la Igualdad. Compendio Normativo 2003-2013, Dirección Nacional de Registro Oficial. Secretaría Legal y Técnica. Presidencia de la Nación, Buenos Aires, 2013. 
Código Civil y Comercial tras 144 años de vigencia de una legislación absolutamente vetusta, anacrónica, individualista, patrimonialista y elitista. U otras decisiones políticas elocuentes como lo fue darle autonomía al desarrollo científico y tecnológico al crear por Decreto 21/2007 el Ministerio de Ciencia, Tecnología e Innovación Productiva.

Los derechos y consecuente empoderamiento que emanan de estas y tantas otras leyes, han cumplido un papel central en esta etapa nacional y popular, signada por una fuerte dosis de una triple " $r$ ": ruptura, resistencia y relato. No por nada somos protagonistas de una sociedad que defiende con el cuerpo la política de derechos humanos bajo el lema de "Memoria, Verdad y Justicia", tal como se lo ha visto en una Plaza de Mayo que rebalsaba de hombres y mujeres agitando con fuerza en el aire pañuelos blancos a modo de un verdadero "grito humano" en contra del nefasto fallo dictado por la Corte Suprema de Justicia de la Nación cuya composición actual es producto también de una determinada época.

En esta misma línea sobre lo que significa, involucra o implica el valor social que emana de diferentes "gritos humanos", cabe traer a colación la lucha que yace detrás de la consigna "Ni una menos" que también es producto de los debates que se han generado gracias al lugar de relevancia que ha tenido la cuestión de género en la agenda pública durante el gobierno $k$.

Como síntesis de este movimiento y movilización social (¿cuánto habrá tenido de útil la investigación social en todo esto?), cabe traer a colación las palabras de la reconocida filósofa norteamericana Judith Butler en "Cuerpos aliados y luchas políticas. Hacia una teoría performativa de la asamblea":

\section{(...) podría pensarse que estas manifestaciones multitudinarias no eran más que una forma de expresar el rechazo colectivo a la precariedad impuesta en términos sociales y económicos. Pero en realidad son mucho más que eso. Lo que vemos cuando los cuerpos se reúnen en la calle, en la plaza o en otros espacios públicos es lo que se podría llamar el ejercicio performativo de su derecho a la aparición, es decir, una reivindicación corporeizada de una vida más visible" (Butler, 2017: 31)}

podría agregarse, de una vida más dignamente vivible ${ }^{18}$. Este derecho a la aparición de diferentes "Todos", visibilizado, gestado y profundizado durante la "docena ganada" es consecuencia, entre otras causas, de un desarrollo de las ciencias sociales activo y activista, en el que pudieron coexistir y retroalimentarse distintos modos y niveles de investigación; en el que también se pudo salir de la falaz contraposición entre teoría y práctica, investigadores de "escritorio" o de "elite" e investigadores de "campo" o "militantes" en el sentido más puro del término, es decir, investigadores que defienden las banderas de justicia social, independencia económica y soberanía política en el campo de la ciencia y técnica, siendo que todo desarrollo científico no puede estar desligado de un determinado modelo de país.

18 Butler, Judith, Cuerpos aliados y lucha política. Hacia una teoría de la performatividad, Paidós, Buenos Aires, 2017, p. 31. 
¿Por qué será que el término "popular" ha tenido tanto rechazo en ciertos ámbitos como el Derecho y la Ciencia? Es cierto que en este último se avanzó mucho entre el 2003-2015, en especial, desde la creación del Ministerio de Ciencia y Tecnología a tal punto que en el tercer piso del edificio del CONICET ubicado en el Polo Científico se aloja un Programa denominado "Popularización de la Ciencia e Innovación”. ¿Acaso las facultades de derecho más recientes, las creadas en dicho período no habría venido a intentar romper con esa lógica elitista, jerárquica y un tanto hipócrita, que tipifican a la enseñanza del derecho y, en definitiva, a la formación de lxs abogadxs? Solo cabe traer a modo de ejemplo, una noticia que acaparó durante varios días la atención de varios medios de comunicación como lo fue haber logrado el título de abogadx personas que son primera camada de profesionales, de condiciones sociales adversas para alcanzar una formación universitaria ${ }^{19}$. Una vez más, fácil se advierten las consecuencias de modelos antagónicos, inclusivos o exclusivos en el acceso a la educación universitaria y a una determinada formación, en el que lo popular forma parte del contexto de vida y a la par, de un modo de ver, entender, transmitir y vivir el Derecho.

\section{Nuevos desafíos}

\subsection{Cuando las voces apocalípticas ya son un recuerdo}

¿Qué nos ha deparado la práctica judicial en las relaciones de familia a dos años de vigencia del CCyC? Varios aportes y en especial, interesantes enseñanzas para quienes hemos tenido la responsabilidad de generar un fuerte y necesario debate que se puede sintetizar en la clara puja auspiciada por la doctrina internacional de los derechos humanos entre un derecho de familia en singular -tradicional y conservador- y un derecho de las familias plural -inclusivo y progresista-

A modo de primera y rápida conclusión. Fácil se puede observar que la nueva regulación civil y comercial no generó ningún "caos" como vaticinaban tantísimos autores aferrados a un derecho y, en definitiva, a una sociedad que ya no existe; siendo la actual absolutamente dinámica, compleja y contradictoria en diferentes sentidos y direcciones. Incluso nada de lo que se pregonaba sucedió en un aspecto puntual como lo es el derecho transitorio que tanto preocupó a uno de los representantes de ese derecho perimido como lo es Julio Rivera quien esgrimió varios reparos críticos en torno a la regulación propuesta en el art. 7 del CCyC. Básicamente y como síntesis para entender el porqué de tal resistencia, este autor coloca en crisis el término "progreso". En este sentido, aseveró que

19 En este sentido, véase: "Mi hijo el doctor”, Página 12, 02/07/2017, disponible en: https://www.pagina12.com.ar/47613-mi-hijo-el-doctor; Emilia Vexler, "La historia de la empleada doméstica que se recibió de abogada para ayudar a su marido preso”, Clarín, 06/07/2017, disponible en: https://www.clarin.com/sociedad/empleada-domestica-recibio-abogada-ayudar-marido-preso_0_SyEoHTjVZ.html; "La caja negra de las universidades nacionales", LA NACIÓN, 09/10/2016, disponible en: http://www.lanacion.com.ar/1945372-la-caja-negra-de-las-universidades-nacionales, compulsados el 25/07/2017. 
no todo lo que se presenta bajo el rótulo 'progreso' es tal. La gran ventaja del progresismo es la denominación que recubre de anticipado valor a ideas que en realidad muchas veces se demuestran después nocivas. Más dudas acarrea este presunto "progreso" si -como se ha visto en ciertas presentaciones del Cód. Civ. y Com.- para imponer ese "progreso" se muestra un hacha que simboliza el modo en que ha de abrirse la cabeza de los abogados y jueces para que les entren algunas de las 'buenas nuevas ideas (Rivera, 2015:1)

En primer lugar, se observa que este autor tendría muy poco sentido del humor. Comenta Kemelmajer en varias de sus charlas una anécdota que compromete a una amiga jurista uruguaya quién con ironía, cuenta que debe dormir con un hacha en la mesa de luz para poder reconocer y aceptar todos los cambios vertiginosos que acontecen en la realidad contemporánea; y que abriéndose la cabeza con la ayuda de ese objeto ha podido comprender y entender el medio en el que tiene que interactuar. Se trata de una manera elocuente y a la vez, pedagógica de decir lo que ha expresado de manera poética y tan elocuente Ricardo Güiraldes -frase muy citada por la mencionada Kemelmajer en varias de sus conferencias dictadas en el marco del debate del entonces Anteproyecto de reforma-: "...Huir de lo viejo. Beber lo que viene. Tener alma de proa". Sin lugar a duda, varios doctrinarios/as se niegan a llevar adelante un acto de valentía como el que propone el recordado autor de "Don Segundo Sombra" y, en definitiva, también lo hace la legislación civil y comercial en la regulación de las relaciones de familia.

Puntualmente, en lo que se refiere al derecho transitorio receptado en el art. 7 del $\mathrm{CCyC}$-siendo una de las excepciones a la regla que allí se propone el tema particular de la filiación derivada por técnicas de reproducción asistida en una de las disposiciones transitorias de la ley 26.994 (art. 9)-, Rivera afirma:

La abrupta entrada en vigencia del Código Civil y Comercial (en adelante "CCyC") es causa de infinitas preocupaciones, dudas y controversias. No puedo dejar de señalar que Aída Kemelmajer de Carlucci -cuyos siempre agudos comentarios y observaciones debo agradecer pues señalan mis errores y me obligan a seguir estudiando el tema- cree en cambio que la aplicación del nuevo Código es más sencilla de lo que algunos comentarios agoreros -entre ellos los míos- anticipaban. Con el máximo respeto por nuestra colega creo que su optimismo nace de una visión parcial, la de los profesores, y quizás la de algunos jueces. Los abogados hemos - por un lado- sumado infinitas dudas sobre la extensión e interpretación de algunos textos cruciales (los contratos de opción, las facultades de los jueces para modificar los contratos aun de oficio, la adecuación de los conjuntos inmobiliarios, la satisfacción de las obligaciones en moneda extranjera, los recursos contra el laudo arbitral, etc., etc.), lo cual -por cierto- es lo que sucede siempre que entra en 
vigencia una nueva ley y se requiere de tiempo para que se consoliden las interpretaciones (Rivera, 2015:149)

Esta afirmación podría ser analizada desde diferentes ángulos, aquí solo nos interesa contrarrestarla con la realidad judicial que, en definitiva, es la que parecería que le interesa al autor que más allá de ejercer la profesión y como bien se dice como "todos los caminos conducen a Roma”, cualquiera sea el lugar desde donde se hable, todos confluyen en la práctica judicial. Desde esta óptica, la jurisprudencia nacional no le devuelve en espejo lo que vaticinaba el autor; todo lo contrario. La cuestión que más debate habría generado en la doctrina como lo es el cambio de sistema de divorcio causado a uno incausado, fue aceptado casi unívocamente por todos los tribunales del país, excepto la Cámara de Apelaciones de Familia de Mendoza que al poco tiempo la Corte Suprema de Justicia de Mendoza se encargó de aclarar y cerrar un debate que quedó en absoluta soledad y ya sorteado ${ }^{20}$.

La misma suerte corrió la cuestión de la obligación alimentaria, en particular, qué sucede con aquellas cuotas alimentarias establecidas en el marco de un divorcio culpable a favor del cónyuge inocente bajo la nueva legislación civil y comercial que derogada el régimen de divorcio causado (subjetivo como objetivo) y por lo tanto o como consecuencia de ello, desaparece del texto legal los alimentos como sanción al cónyuge culpable. La jurisprudencia no observó un acalorado debate como se vaticinaba, sino que en la actualidad es conteste en sostenerse que tales obligaciones quedaron extinguidas desde el 01/08/2015²1. Una vez más, Rivera esgrimió su crítica a

20 En esta línea ver, entre otros: Suprema Corte de Justicia de Mendoza, Sala I, 02/03/2017, "B. V. c/ O. S. s/ divorcio vincular contradictorio", El Dial online Cita: MZ5748; Suprema Corte de Justicia de Mendoza, Sala I, 06/02/2017, “.M.G. c/ S.C.S. s/ divorcio vincular contencioso”, Microjuris online Cita: MJ-JU-M-102823-AR | MJJ102823 | MJJ102823; Suprema Corte de Justicia de Mendoza, Sala I, 11/03/2016, "P., M. A. del R. c/ A., J.A. s/ divorcio vincular contencioso - división de sociedad conyugal", LLGran Cuyo 2016 (agosto), 7 Cita online: AR/JUR/13582/2016 y Suprema Corte de Justicia de la Provincia de Mendoza, Sala I, 22/03/2016, ”M. F. A. c/ A. I. s/divorcio vincular contencioso", Microjuris online Cita: MJ-JU-M-97396-AR | MJJ97396.

Asimismo, varios trabajos han comentado la cuestión como ser: Ciolli, María Laura y Albornoz, María Claudia del V., "Interpretación del artículo 7 del Código Civil y Comercial de la Nación en el divorcio incausado", Sup. Doctrina Judicial Procesal 2016-1, 25 Cita Online: AR/DOC/4084/2015; Culaciati, Martín Miguel, "La aplicación inmediata del Código Civil y Comercial a los divorcios en trámite sin sentencia firme”, LLBA 2015 (diciembre), 1190 Cita Online: AR/DOC/3608/2015; Hayes, Ricardo Rubén Enrique y Pandiella Molina, Juan Carlos, "Divorcio vincular contencioso. Aplicación del Código Civil y Comercial", LlGran Cuyo 2015 (diciembre), 1165 Cita Online: AR/DOC/4060/2015; Molina de Juan, Mariel F., "No hay más inocentes ni culpables en el divorcio argentino", LA LEY 18/05/2016, 5 Cita Online: AR/DOC/1494/2016 y Yuba, Gabriela, "La aplicación del art. 7 del Código Civil y Comercial en un caso de divorcio", DFyP 2015 (octubre) , 93 Cita Online: AR/DOC/3211/2015.

21 Recomendamos compulsar como primer fallo en este sentido y por ende, el que marcó el rumbo de la cuestión en la jurisprudencia nacional el dictado por la Sala I de la Cámara Nacional de Apelaciones en lo Civil, 01/12/2015, "M. L., N. E. c. D. B., E. A. s/ alimentos" (LA LEY 30/05/2016, 4 Cita Online: AR/JUR/70851/2015) y los comentarios generados en la doctrina: Castro, Verónica A., "Alimentos devenidos de la culpabilidad en un divorcio causado", RCCyC 2016 (julio), 79 Cita Online: AR/DOC/1114/2016 y Kemelmajer de Carlucci, Aída, Herrera, Marisa y Molina de Juan, Mariel F., "La obligación alimentaria del cónyuge inocente y el derecho transitorio. cuando las piezas se van acomodando", LA LEY 30/05/2016, 4 Cita Online: AR/DOC/1550/2016. 
esta postura jurisprudencial que ha tenido buena recepción en la doctrina al aseverar que

más allá de la opinión de Roubier y del evidente cambio de modelo de familia matrimonial y de los deberes causados en ella, así como de la supresión de la noción de culpa en el divorcio, el crédito alimentario reconocido al amparo de la legislación anterior subsiste, pues su privación por la nueva legislación afectaría la garantía constitucional de la propiedad. Y si se concretara la privación de tal crédito, ello comprometería la responsabilidad del Estado por acto lícito"; por lo tanto, sostiene que "ese crédito es inconstitucional (Rivera 2017: 1)

¿Un crédito puede ser declarado "inconstitucional”? ¿Y una ley -el CCyC- ser declarado tal por no mantener una obligación que era entendible en el marco de un sistema que buscaba vencidos y vencedores en una cuestión tan compleja como íntima como lo son las relaciones matrimoniales? ${ }^{22}$

En definitiva, fácil se puede concluir una vez más que "todos los caminos conducen a Roma”; que la cuestión del derecho transitorio no es una crítica a este tema pasajero ya que con el tiempo va perdiendo interés práctico, sino que detrás de él se esconden las mismas críticas que generó la regulación de las relaciones de familia en el entonces Anteproyecto y ahora CCyC; es decir, la necesaria y sana tensión entre lo nuevo y lo viejo, un derecho de familia pacato, elitista, para unos pocos y un derecho de las familias, con la riqueza y la complejidad que se derivan de las relaciones de afecto en un país del tercer mundo en el que los derechos sociales, económicos y culturales, en el que las diferentes identidades están -y en buena hora- muy presentes.

\subsection{Cuán fuerte es el envión progresista}

\section{2.a. Una quita que toma un protagonismo ascendente}

Siguiéndose con el principio de realidad y la imagen que nos devuelve el espejo jurídico al cual nos debemos enfrentar, entiendo interesante destacar dos temáticas que cada vez alcanzan un lugar de mayor preponderancia e interés en la doctrina y jurisprudencia nacional. Nos referimos a la figura de la gestación por sustitución y la denominada "triple filiación" y la consecuente puesta en crisis de un principio central en el derecho filial tradicional. Aquí nos focalizaremos en el primero: en la gestación por sustitución (GS) desde una perspectiva crítica como la que siempre se ha seguido, es decir, pretendiendo problematizar qué hay detrás o por delante de las normas o las propuestas legislativas, qué intereses las movilizan, qué facetas se excluyen o silencian y qué tensiones generan.

22 Se recomienda estar atentos a las conclusiones que se arriben en la comisión de familia de las XXVI Jornadas Nacionales de Derecho Civil a realizarse en la ciudad de La Plata, ya que estas voces conservadoras se harán sentir con fuerza como reacción a todos los avances que han operado en el derecho argentino en los últimos años y en el que cabe colocar como hito normativo la ley 26.618; en lo personal, de gran orgullo legislativo nacional. 
Como bien se lo define en uno de los cuatro proyectos que se encuentran en la Cámara de Diputados al momento en que se redacta el presente ensayo, la GS "constituye un procedimiento de técnicas de reproducción médicamente asistida por medio del cual una persona, denominada gestante, lleva adelante un embarazo con el fin de que la persona nacida tenga vínculos de filiación con una persona o pareja denominada comitente/s con quien/es la gestante posee lazos afectivos"23.

Si bien esta figura pretendía ser regulada en el texto civil y comercial y así lo propuso el entonces Anteproyecto de Reforma, esta iniciativa quedó trunca durante el debate parlamentario por presión de dos actores antagónicos: la Iglesia Católica -actor social opositor por naturaleza a todos los avances o progresos legislativos en el campo de las relaciones de familia- y voces provenientes del feminismo más radical. Como se suele decir en política, a veces los extremos se parecen, concluyen o se unen, si bien por argumentos bien disímiles, pero con resultados o conclusiones similares.

Ahora bien, qué ha sucedido desde entonces. En primer lugar, cabe un reconocimiento a aquella iniciativa frustrada porque gracias a ella, el tema no sólo ha sido instalado -y por ende, visibilizado- en el derecho argentino, sino que también habría marcado un modo de tratamiento de la temática en el que se pretendía desde sus orígenes, proteger a la mujer gestante reconociendo que es la persona más vulnerable de todos los protagonistas en las historias de GS; incluso, más que el niño o niña que pudiera nacer de esta especial técnica de reproducción asistida, ya que en este caso, el niño o niña aún no ha nacido y por lo tanto, la persona más débil en la primera etapa de la GS es la gestante. Más aún, centrándose en el niño o niña ya nacido de este modo, cabría preguntarse cuál es la incidencia en la construcción de vínculos de afecto genuinos y transparentes plataformas legales que permitan relaciones claras, seguras y previsibles en tal edificación de parentalidades contemporáneas.

La segunda cuestión que vale destacar, gira en torno a un principio que ha estado muy presente a modo de cimiento en la redacción del ahora vigente $\mathrm{CCyC}$, me refiero al principio de realidad. Si bien cuando se estaba redactando el Anteproyecto sólo se tenía conocimiento del primer planteo judicial de GS realizado en el país y al poco tiempo, el segundo caso que terminó siendo por cuestiones procedimentales o formales, la primera sentencia sobre esta temática, el sentenciado por el Juzgado Nacional en lo Civil nro. 86 de Capital Federal en fecha 18/06/2013 24 ; lo cierto es que hasta la actualidad ya se cuentan con un total de 19 precedentes que dan cuenta ${ }^{25}$, de manera

23 Art. 3 del proyecto 5759-D-2016 que quien suscribe ha formado parte del equipo interdisciplinario de redacción presentado por un grupo de diputados del FPV, encabezado por la chaqueña Analía Rach Quiroga.

24 Juzgado Nacional de Primera Instancia en lo Civil Nro. 86, 18/06/2013, "N.N. o D. G., M. B. M. s/inscripción de nacimiento”, LA LEY 01/07/2013, 2 Cita Online: AR/JUR/23081/2013

25 Además del mencionado primer fallo, le han seguido los restantes 18 precedentes que de manera ascendente son los siguientes: 1) Juzgado de Familia, Gualeguay, 19/11/2013, "B.M.A. c. F.C.C.R. s/ ordinario" (LA LEY 2013-D, 195 Cita Online: AR/JUR/89976/2013); 2) Tribunal Colegiado de Familia Nro. 7, Rosario, 2/12/2014, "XXX s/ maternidad por sustitución" (RDF 2016-III, 135 Cita Online: AR/JUR/90178/2014); 3) Juzgado Nacional de Primera Instancia en lo Civil Nro. 102, 18/5/2015, “C., F. A. y otro c. R. S., M. L. s/impugnación de maternidad” (LA LEY 2015-C, 522 Cita Online: AR/JUR/12711/2015); 4) Juzgado Nacional de Primera Instancia en lo Civil Nro. 83, 25/6/2015, "N.N. O s/ inscripción de nacimiento” (La Ley Cita Online: AR/JUR/24326/2015); 5) Juzgado Familia Nro. 1, Mendoza,29/7/2015, "A. C. G. y otro s/ medida 
elocuente, que la GS es una realidad social instalada en la jurisprudencia y doctrina nacional ${ }^{26}$.

Ahora bien, cuál es la razón por la que en épocas de franco retroceso en la ampliación de derechos, incluidos los derechos civiles de tinte familiares, un tema tan polémico como vanguardista vuelva ser parte del debate o se la incluya en la agenda pública legislativa.

Una respuesta sencilla que se podría ensayar se centra en el lugar protagónico de los medios de comunicación. Nos explicamos mejor. El caso del conductor Marley y de la vedette Salazar, habrían vuelto a poner en escena el tema de la GS. Si bien ambos casos tratan de procedimientos realizados en el exterior, ello habría disparado también el abordaje del tema en sí que compromete también las situaciones ascendentes o cada vez de mayor presencia de GS a nivel nacional. Sucede, que justo a la par, se dictó y

autosatisfactiva" (ED 264, 409 Cita online: AR/JUR/28597/2015); 6) Juzgado de Familia Nro. 1, Mendoza, 15/12/2015, "C.M.E. y J.R.M. s/ inscripción nacimiento" (disponible en: http://www.colectivoderechofamilia.com/fa-pcial-juz-flia-no1-mendoza-gestacion-por-sustitucion/, compulsado el 25/7/2017); 7) Juzgado de Familia Nro. 9, Bariloche, 29/12/2015, “autos reservados" (La Ley Cita online: AR/JUR/78613/2015); 8) Juzgado Familia Nro. 7, Lomas de Zamora, 30/12/2015, "H. M. y otros s/ medidas precautorias art. 232 del CPCC” (LA LEY 02/05/2016, 6 Cita online: AR/JUR/78614/2015); 9) Tribunal Colegiado de Familia Nro. 5, Rosario, 27/05/2016, “S. G. G. y otros s/ filiación” (RDF 2017-I, 121 Cita online: AR/JUR/37971/2016); 10) Juzgado Nacional de Primera Instancia en lo Civil Nro. 7, 15/06/2016, "A.R.C. y otros c/C.M.J. s/impugnación de filiación" (Inédito); 11) Juzgado Nacional de Primera Instancia en lo Civil Nro. 4, 30/06/2016, "S.T.A. y otro s/inscripción de nacimiento" (Inédito); 12) Juzgado de Familia Nro. 2, Moreno, 04/07/2016, “S. P., B. B. c. S. P., R. F. s/ materia a categorizar" (La Ley Cita Online: AR/JUR/42506/2016); 13) Juzgado de Familia Nro. 3, General San Martín, 22/08/2016, "M.I.M. y otros s/autorización judicial” (Inédito); 14) Juzgado Nacional de Primera Instancia en lo Civil Nro. 8, 20/09/2016, "B. B. M. y otro c/ G. Y. A. s/ impugnación de filiación” (Microjuris online MJ-JU-M-100901-AR | MJJ100901 | MJJ100901); 15) Juzgado de Familia Nro. 12, Lomas de Zamora, 03/10/2016, "G.M.C. y otro c/ W.B.A.V. s/rectificación de partidas" (Inédito); 16) Juzgado de Familia Nro. 7, Lomas de Zamora, 30/11/2016, "B. J. D. y otros s/ materia a categorizar" (La Ley Cita Online: AR/JUR/85614/2016); 17) Juzgado Nacional de Primera Instancia en lo Civil nro. 81, 14/06/2017 (Rubinzal Online Cita: RC J 3934/17) y 18) Juzgado de Familia Nro. 7, Viedma, 06/07/2017, "Reservado s/ autorización judicial" (Microjuris online Cita: MJ-JU-M-105310-AR | MJJ105310 | MJJ105310.

26 Vastísimo es el material bibliográfico al respecto, sólo para citar los publicados durante los años 2016-2017 citamos los siguientes: Escudero de Quintana, Beatriz, "Análisis jurisprudencial sobre gestación por sustitución: reflexiones en torno a la situación de la madre portadora”, El dial online Cita: DC2324; Feldstein de Cárdenas, Beatriz, "La doctrina del tribunal europeo en materia de maternidad subrogada: análisis de un fallo ejemplar", El dial online Cita DC2308; Gómez Haiss, Dante D., "Gestación por sustitución. Necesaria existencia de una ley especial en la Argentina”, Microjuris online Cita: MJ-DOC-10756-AR| MJD10756; González, Andrea, Melón, Pablo y Notrica, Federico, "La gestación por sustitución como una realidad que no puede ser silenciada", Microjuris online Cita: MJ-DOC-7570-AR | MJD7570; Herrera, Marisa, Lamm, Kemelmajer de Carlucci, Aída, Eleonora y De la Torre, Natalia, La gestación por sustitución en el Tribunal Europeo de Derechos Humanos. A propósito del caso "Paradiso y Campanelli c. Italia", La Ley 13/03/2017, 6 Cita Online: AR/DOC/610/2017; Herrera, Marisa y De la Torre, Natalia, "La gestación por sustitución nuevamente en la agenda legislativa”, La Ley 03/11/2016, 1 Cita Online: AR/DOC/3039/2016; Jáuregui, Rodolfo G., "La gestación por sustitución y la laguna del Código Civil y Comercial. Un fallo que explora una solución posible”, LLLitoral 2016 (agosto) , 3 Cita Online: AR/DOC/2296/2016; Monzón, José M. "El «sí» judicial a la maternidad subrogada. Análisis del fallo «H. M. y otro/a» del Juzgado de Familia N. 7 de Lomas de Zamora”, Microjuris online Cita: MJ-DOC-9850-AR| MJD9850; Notrica, Federico, "Gestación por sustitución nacional: Derecho y realidad”, Revista de Derecho Privado y Comunitario, 2016-1, Santa Fe, Rubinzal-Culzoni, 2016, pp. 215-256; Notrica,F, Curti, P, Cotado, F, "La figura de la gestación por sustitución”, en Revista del Instituto de Ciencias Jurídicas de Puebla, México, Volumen 11, Número 39, 2017, disponible en: http://www.scielo.org.mx/scielo.php?script=sci_arttext\&pid=S1870. 21472017000100008, compulsado el 25/7/2017 y Yuba, Gabriela, "Gestación por sustitución y regulación normativa”, RCCyC 2016 (noviembre) , 113 Cita Online: AR/DOC/3298/2016. 
difundió con fuerza la sentencia número 19 de GS nacional dictada por el Juzgado de Familia de Viedma en fecha 06/07/2017 ${ }^{27}$. Se trata de un supuesto que justamente, sigue la misma lógica del Anteproyecto y del proyecto 5759-D-2016 (reafirmado por copia textual, del proyecto presentado por Carrizo, el 3202-D-2017), es decir, involucra un pedido de autorización judicial previa al procedimiento de GS solicitado por una pareja conformada por dos hombres y la íntima amiga de uno de ellos quién sería la persona que llevaría adelante la gestación con óvulo proveniente de banco y el esperma de uno de los miembros de la pareja que quieren ser padres. Este fallo es el cuarto de autorización judicial y también el cuarto que compromete a una pareja de varones.

En este contexto en el que la realidad social se impone magnificada por el poder de los medios de comunicación ${ }^{28}$, es que la cuestión volvió a tener su espacio en el debate

27 Juzgado de Familia Nro. 7 Viedma, 06/07/2017, op.cit.

28 Como síntesis del poder mediático, vale hacer un breve panorama por la prensa escrita y destacar los diferentes titulares que generaron el caso de Marley, Salazar y el fallo de Viedma por ser los eventos más recientes en la temática en análisis: "Marley papá y el boom de los "vientres en alquiler"', Infobae, 04/06/2017, disponible en: $\quad$ http://www.infobae.com/salud/ciencia/2017/06/04/marley-papa-y-el-boom-de-los-vientres-en-alquiler/; "Marley será papá por alquiler de vientre: "Se va a llamar Mirko", Tiempo de San Juan, 01/06/2017, disponible en: http://www.tiempodesanjuan.com/espectaculos/2017/6/1/marley-sera-papa-alquiler-vientre-se-llamar-mirko-

178431.html; "Alquiler de vientre: la vía que eligieron Marley y Luciana Salazar para tener un hijo", Caras, 11/07/2017, disponible en: http://caras.perfil.com/2017-07-11-144483-alquiler-vientre-la-via-eligieron-marleyluciana-salazar-hijo/; "Marley será papá mediante un alquiler de vientre en EE.UU.", La nueva, 01/07/2017, disponible en: http://www.lanueva.com/aplausos/904821/marley-sera-papa-mediante-un-alquiler-de-vientre-enestados-unidos.html; "Marley será padre: "Hice un alquiler de vientre", EL DIA, 01/07/2017, disponible en: http://www.eldia.com/nota/2017-6-1-23-4-35-marley-sera-padre-hice-un-alquiler-de-vientre-espectaculos; "El médico de Luciana Salazar reveló por qué será mamá a través del alquiler de vientre: "Ella tiene trombofilia, por eso la subrogación"', Ciudad magazine, 11/07/2017, disponible en: http://www.ciudad.com.ar/espectaculos/medico-luciana-salazar-revelo-que-sera-mama-traves-alquiler-vientre-ellatiene_85701; “Por qué Luciana Salazar eligió el método de subrogación de vientre para ser madre?”, Teleshow, 11/07/2017, disponible en: http://www.infobae.com/teleshow/infoshow/2017/07/11/por-que-luciana-salazareligio-el-metodo-de-subrogacion-de-vientre-para-ser-madre/; Ubfal Laura, "Luciana Salazar, madre por vientre de alquiler", LAUBFAL, 11/07/2017, disponible en: http://laubfal.com/luciana-salazar-madre-por-vientre-dealquiler/;"Conocé a la dueña del vientre que alquiló Luciana Salazar", Pronto, 11/07/2017, disponible en: http://www.pronto.com.ar/articulo/famosos/conoce-duena-vientre-alquilo-luciana-

salazar/20170711104319247723.html; "Los motivos por los que Luciana Salazar optó por alquilar un vientre para ser madre", Mitre, 11/07/2017, disponible en: https://radiomitre.cienradios.com/los-motivos-por-los-que-lucianasalazar-opto-por-alquilar-un-vientre-para-ser-madre/; Pecollo Adrián, "Alquiler de vientre: autorizan en Viedma el primer caso del pais", De Viedma, 09/07/2017, disponible en: http://www.rionegro.com.ar/viedma/alquiler-devientre-autorizan-en-viedma-el-primer-caso-del-pais-CI3129488; "Viedma: autorizan el primer alquiler de vientre", Ahora Río Negro, 09/07/2017, disponible en: http://www.ahorarionegro.com/noticia/9401-viedma-autorizan-elprimer-alquiler-de-vientres; "Autorizan el primer caso del país de alquiler de vientre", Diario Registrado, 10/07/2017, disponible en: http://www.diarioregistrado.com/sociedad-/autorizan-el-primer-caso-del-pais-dealquiler-de-vientre_a5963b592d669e67b19cfd05b; "Autorizan a una pareja gay de varones a engendrar un hijo por "alquiler de vientre"”, EL DIA, 10/07/2017, disponible en: http://www.eldia.com/nota/2017-7-10-4-33-30autorizan-a-una-pareja-gay-de-varones-a-engendrar-un-hijo-por-alquiler-de-vientre-informacion-general; "La justicia autorizó el primer caso de alquiler de vientre en el pás", Centediario, 10/07/2017, disponible en: http://www.centediario.com/la-justicia-autorizo-el-primer-caso-de-alquiler-de-vientre-en-el-pais/; "Viedma: autorizan a una pareja homosexual a alquilar un vientre", Tu noticia, 09/07/2017, disponible en: http://www.tunoticia.com.ar/viedma-autorizan-a-una-pareja-homosexual-a-alquilar-un-vientre/; "Alquiler de vientres: en Córdoba esperan fallos", Dos miradas, 10/07/2017, disponible en: http://dosmiradas.com.ar/?p=6049 y "Autorizaron el primer alquiler de vientre en Río Negro", Diario popular, 10/07/2017, disponible en: https://www.diariopopular.com.ar/general/autorizaron-el-primer-alquiler-vientre-rionegro-n314129. 
parlamentario. A los dos proyectos presentados en el 2016 y que aún mantienen estado parlamentario como lo son el proyecto 5700-D-2016 encabezado por la diputada Araceli Ferreyra del Movimiento Evita y el 5759-D-2016 encabezado por la diputada Analía Rach Quiroga del Frente para la Victoria -ambos presentados el 31/08/2016-; de manera más reciente y a raíz de estas situaciones mediatizadas se presentó el 14/06/2017 el proyecto 3202-D-2017 por el diputado Lipovetsky del PRO y posteriormente, el 10/07/2017 el proyecto 3765-D-2017 de la radical Carla Carrizo que integra la Alianza Cambiemos.

Para poder comprender con mayor exactitud los debates jurídicos y en el fondo, políticos que se dirime al analizar la GS en el derecho nacional, cabe poner de resalto dos consideraciones. La primera, el proyecto presentado por el Movimiento Evita a través de la diputada Ferreyra y el del diputado Lipovetsky han sido elaborados por la misma pluma, es decir, por la Federación Argentina de Lesbianas, Gays, Bisexuales y Trans (FALGBT). La segunda cuestión es que el proyecto presentado por la diputada Carrizo es casi textual del proyecto presentado por la diputada Rach Quiroga, por lo tanto, el interrogante que se deriva es la razón para no firmar y así acompañar un proyecto legislativo que ya estaba presentado. A lo mejor en tiempos electorales, valgan más decisiones individuales, aunque ello contraríe o ponga en crisis la ética de una conducta legislativa inapropiada como lo es copiar casi textual un proyecto de ley aún vigente y presentado por otra fuerza política.

En este contexto, fácil se advierte que el debate legislativo gira en torno a dos propuestas, la del Movimiento Evita y el Pro que irían o tendrían una estrategia o agenda legislativa conjunta en el tema de la GS, o al menos por parte del presidente de la comisión de Legislación General que está en cabeza del mencionado Lipovetsky que además es la comisión cabecera o en la cual se empezaron a debatir todos estos proyectos; y el presentado por una parte del FPV bajo la autoría de Rach Quiroga acompañada en definitiva, por la diputada Carrizo.

La diferencia sustancial reside en la recepción de un proceso judicial previo en el que se peticione, evalúe y decida un juez especializado y su equipo técnico ante el pedido de autorización para la realización de la gestación por sustitución. En otras palabras, que ningún centro de salud habilitado pueda llevar adelante el procedimiento de GS si no se cuenta con la debida autorización judicial. ¿A qué se debe este control estatal a través de la justicia de este tipo especial de técnica de reproducción asistida? Principalmente, en resguardo y protección de los derechos de la gestante y a la par o, en definitiva, de todos los intervinientes en un proceso como este en el que se apela al cuerpo y la salud en sentido amplio como lo define la Organización Mundial de la Salud ${ }^{29}$ - para un proyecto parental de una o dos personas que no ponen en riesgo su cuerpo ni salud. ¿Acaso la construcción de futuros vínculos filiales mediante reglas claras que brinden seguridad y previsibilidad no constituye un beneficio para todos los involucrados, incluido el centro médico especializado?

29 "La salud es un estado de completo bienestar físico, mental y social, y no solamente la ausencia de afecciones o enfermedades". Cfr. Preámbulo de la Constitución de la Organización Mundial de la Salud, disponible en: http://www.who.int/suggestions/faq/es/; compulsado el 25/07/2017. 
Regular un proceso judicial previo permite poder evaluar cada situación que se presente y a la par, establecerse ciertos requisitos a modo de límites y así protección a las mujeres gestantes como ser: que las gestantes hayan tenido un hijo propio a los fines de saber lo que implica un embarazo por haberlo vivenciado con el consecuente aporte en términos de alcanzar un consentimiento lo más informado posible; que la gestante no aporte su propio material genético a los fines de evitar posibles conflictos en materia de arrepentimiento dado que los planteos complejos presentados en el derecho comparado han sido situaciones de gestantes que además fueron aportantes de óvulo y por lo cual la unía un vínculo genético con el o la niña; que la gestante lleve adelante un embarazo para terceros hasta un máximo de dos veces para evitar el uso y abuso de su cuerpo e incurrir en una nueva forma o modalidad contemporánea de explotación. A tal fin, se prevé la creación de un registro en el que se deberían inscribir todas las sentencias de autorización judicial de GS que se dicten en el país a los fines de llevar información actualizada de dicho número y la correspondiente protección de las mujeres en atención al límite mencionado y su efectivo cumplimiento. Por otra parte, y al igual que acontece con la filiación adoptiva, se establece que tanto la gestante como el o las personas que quieren ser padres (quienes prestan la correspondiente voluntad procreacional) deben cumplir con un lapso de residencia mínima en el país de 5 años a los fines de evitar el turismo reproductivo, máxime en países del tercer mundo como el nuestro y en momentos socioeconómicos difíciles en atención a las mencionadas políticas de ajuste. Por último, en el proyecto en análisis, el 5759-D-2016, se prevé la compensación económica por los gastos y las molestias que implica llevar adelante un embarazo cuyas variables para cuantificar este monto debería definir la Autoridad de Aplicación de la ley 26.862, es decir, el Ministerio de Salud de la Nación. De este modo, se sale de la falsa disyuntiva entre GS altruista o GS lucrativa, siendo un saldo cualitativo importante y equilibrado referirse a la idea de compensación; máxime cuando hay situaciones en las que la gestante es familiar de quiénes quieren ser padres y también sería injusto que tales gastos y molestias no se vean compensados. Y a la par, la cuestión del lucro sería mitigada desde una doble vía o mediante una herramienta doble: la compensación económica y el máximo de veces aludido.

Los otros dos proyectos elaborados por la Federación no prevén ninguna protección a las mujeres gestantes. Parecería que se debería caer en la falsa tensión entre derechos de las mujeres vs derechos de las personas LGBTI y ello no es así como bien se puede concluir del modo en que se regula la GS en el proyecto 5759-D-2016. No se debe explotar a las mujeres o dejarlas al libre juego de oferta y demandapara que las parejas del mismo sexo -en especial conformada por dos hombres- sean padres en defensa del principio de igualdad y no discriminación debido a la orientación sexual. Es claro que la GS es el único modo que las parejas del mismo sexo de varones pueden alcanzar la copaternidad, pero ello no debe serlo a costa de la explotación del cuerpo de las mujeres. Por otra parte, tal supuesta explotación no lo sería sólo por parte de este grupo social, sino que también lo es de todas las parejas de diverso sexo cuyas mujeres no pueden llevar adelante un embarazo por diferentes motivos.

En suma, si las políticas de ajuste en sí conculcan derechos humanos en diferentes planos, sentidos y direcciones; no cabe perder de vista también el impacto de esta 
temática en el campo de la GS. Sucede que sólo mediante debates profundos -y la política es, en definitiva, hábil para colaborar de manera activa en esa línea- se podría alcanzar una normativa que realmente proteja a los más débiles. Como es sabido, el fuerte ya por serlo se encuentra en una situación de ventaja, es por ello que la ley debe ser una herramienta de gran utilidad para los más vulnerables; precisamente, son ellos quienes necesitan del auxilio de la ley para poder estar en una situación de mayor horizontalidad; o en otras palabras, de menor sumisión, explotación y abuso.

\section{2.b. Un debate pendiente que no es para cualquiera}

Es sabido que el CCyC mantiene el principio binario por el cual nadie puede tener más de dos vínculos filiales, más allá del sexo y género de cada uno de sus progenitores(art. 558 última parte); es decir, madre- padre, madre- madre o padre- padre, pero siempre se debe cumplir con un máximo de dos vínculos filiales. En otras palabras, menos sí (filiación unilateral o filiación desconocida), pero más de dos no.

Ya durante el debate del entonces Anteproyecto de reforma, algunas voces criticaban que se siguiera esta postura tradicional y fundante del derecho filial y por ende, proponían su apertura y la consecuente posibilidad de que un niño o niña tuvieran tres o más vínculos filiales como se empezaba a vislumbrar en unos pocos, poquitísimos, ordenamientos jurídicos (algún estado de Estados Unidos como California que se generó un debate al respecto, o la Ley de Familia del Estado de Columbia Británica, Canadá, vigente desde 2013 o cierto reconocimiento jurisprudencial que ha acontecido en Brasil $^{30}$ ). Ahora bien, nuevamente apelándose a la perspectiva realista, cabe preguntarse qué viabilidad existía para que el Congreso Nacional pudiera sancionar una postura legislativa casi novedosa a nivel mundial lo que implicaba, de base, reformar una gran cantidad de normativas del Anteproyecto relativas a la responsabilidad parental que es el conjunto de derechos y deberes que se deriva de la filiación. Es decir, mayor cantidad de lazos filiales obliga a ampliar las relaciones parentales y, por lo tanto, la legislación civil debería haber reformulado todo el régimen en la materia incluso, resolver determinados conflictos que podrían acontecer si por ejemplo, dos de los tres progenitores están de acuerdo y prestan el correspondiente consentimiento para un hijo

30 Para profundizar sobre la cuestión en el derecho comparado ver entre otros: De la Torre, Natalia, "Pluriparentalidad: ¿por qué no más de dos vínculos filiales?", RDF 2015-VI-217 Cita Online: AP/DOC/1075/2015; De Lorenzi, Mariana A., "La aritmética de la filiación: cuando no hay dos sin tres, pero tres son multitud. El imperativo real de la pluriparentalidad”, RDF 2017-79-227 Cita Online: AP/DOC/251/2017; Herrera, Marisa, "Socioafectividad e infancia ¿De lo clásico a lo extravagante?” en Fernández Silvia (directora), Tratado de derechos de niñas, niños y adolescentes, Albeledo Perrot, CABA, 2015, Tomo I, pp. 971- 1012; Haim Abraham, "A FamilyIsWhatYouMakeIt? Legal Recognition and RegulationofMultipleParents", American UniversityJournalofGender, Social Policy\&the Law, Forthcoming, 2017, disponible en: https://papers.ssrn.com/sol3/papers.cfm?abstract_id=2925886, compulsado el 25/07/2017, Herrera, Marisa, "La noción de socioafectividad como elemento "rupturista" del derecho de familia contemporáneo", RDF 66-75 Cita online: AP/DOC/1066/2014; Lamm, Eleonora y Rodríguez Iturburu, Mariana, "Familias multiparentales" en Kemelmajer de Carluci, Aida, Herrera Marisa y Lloveras Nora (directoras), Tratado de Derecho de Familia: actualización doctrinal y jurisprudencial, Santa Fe, Rubinzal Culzoni, 2016, Tomo VA, pp.808-820; Lewis, Myrisha S., "Biology, genetics, nurture, and thelaw: theexpansionofthe legal definitionoffamilytoincludethreeor more parents", Heinonline, cita:16 Nev. L.J. 743 2015-2016; Peralta, María L., "Filiaciones múltiples y familias multiparentales: la necesidad de revisar el peso de lo biológico en el concepto de identidad" Thomson Reuters Cita Online: AP/DOC/57/2015. 
menor de edad viaje al exterior pero el tercer progenitor se negare. ¿En ese caso, debería intervenir la justicia o se debería aplicar la regla de la mayoría? Como se puede observar, es mucho más fácil esgrimir críticas que construir posibles soluciones y dar respuestas normativas claras y precisas a los supuestos de triple o más filiaciones. Justamente, proponer una regulación al respecto no es una tarea sencilla y tampoco estaban dadas las condiciones jurídicas y políticas para avanzar en un campo que aún está muy fértil. Máxime, en el marco de un ordenamiento jurídico que recepta el sistema de control de constitucionalidad difuso por el cual, cuando se presente un supuesto especial, el juez puede reconocer la triple filiación y para ello, declarar la inconstitucionalidad del art. 558 en su última parte que limita los vínculos filiales a un máximo de dos. Esta conclusión fue la arribada en las XXV Jornadas Nacionales de Derecho Civil realizadas en la ciudad de Bahía Blanca en el 2015 en el que uno de los ejes de debate fue, precisamente, la cuestión compleja de al triple filiación ${ }^{31}$.

¿A qué se debe este interés concreto por situaciones que aún siguen siendo excepcionales? Precisamente, la excepción implica que este tipo de planteos acontecen, que están en la práctica -aunque sea de manera esporádica- y de conformidad con el mencionado principio de realidad que obliga a enfrentarnos a una mayor pluralidad de formas de organización familiar, debe darse una respuesta jurídica concreta. ¿En qué sentido o en qué dirección, positiva -a favor de la triple filiación- o por la negativa?

Veamos, durante el año 2015 se presentaron dos casos ante el Registro Civil que comprometen planteos de triple filiación en el marco de una relación conformada por dos mujeres en el que quienes aportan el esperma no lo hacen en calidad de "donante", sino que también quieren ser reconocidos como padres y se comportan o ejercen funciones de tal. Es decir, se trata de niños criados por estos tres adultos. Aquí, los registros civiles intervinientes -el de la Provincia de Buenos Aires primero y después el de la Ciudad de Buenos Aires- hicieron lugar al reconocimiento efectuado por el hombre después de que el niño tuviera ya determinado el vínculo con ambas mujeresmadres, y emitieron una nueva partida, constando el triple vínculo filial ${ }^{32}$.

Tiempo más tarde, ya en el 2016, se presentó otro caso ya vigente el CCyC que debió ser judicializado. ¿La razón? Básicamente política, es que cambió el gobierno y, por ende, los funcionarios del registro civil y con ello la mirada ahora negativa de este tipo de conformación familiar que se sale del estándar, tradicional o "normal" para quienes aún creen -de manera simplista y un tanto superficial- que las personas y las relaciones familiares que ellas generan se pueden clasificar en "normales" y "anormales". Se trata

31 Cabe recordar que el despacho de mayoría sostuvo: "En los casos de pluriparentalidad es posible declarar la inconstitucionalidad del artículo 558 del Código Civil y Comercial de la Nación". Por su parte, el de minoría expresó: "Los casos de pluriparentalidad pueden ser resueltos a partir de una lectura sistémica de todo el código, en particular de los artículos 1 y 2 del Título Preliminar". Cfr. Conclusiones de la Comisión Nro. 6 de Familia: "Identidad y filiación", en las XXV Jornadas Naciones de Derecho Civil, 2015, disponible en: http://jndcbahiablanca2015.com/wp-content/uploads/2015/10/CONCLUSIONES-06.pdf, compulsado el 25/07/2017.

32 Cfr. Duprat, Carolina, Herrera, Marisa y Pellegrini, María V., "Filiación e identidad: principales desafíos del derecho filial contemporáneo en el Código Civil y Comercial de la Nación”, Revista Código Civil y Comercial. Edición Especial XXV Jornadas Nacionales de Derecho Civil La Ley Thomson Reuters, 2015, pp. 93 a 110 y Peralta, María L., "Filiaciones múltiples y familias multiparentales: la necesidad de revisar el peso de lo biológico en el concepto de identidad", op.cit., pp. 53-70. 
de un caso acontecido en Mar del Plato en el que una mujer junto a su mejor amigo y la pareja de este, deciden los tres, tener un hijo mediante el aporte de material genético de la mujer y el semen de la pareja de su mejor amigo. Los tres, más allá del aporte de gametos de dos de ellos, exteriorizan su voluntad procreacional en el correspondiente consentimiento informado de conformidad con las reglas que dispone el Código Civil y Comercial vigente desde agosto del 2015 que, precisamente, regula de manera especial y autónoma las $\mathrm{TRHA}^{33}$ y, por lo tanto, sólo interesa a los fines de la determinación de la filiación quién/es prestan la voluntad procreacional debidamente plasmado en un consentimiento informado. Los tres, cada uno por separado, exteriorizó su deseo de ser progenitor cumpliéndose con todos los requisitos que establece el $\mathrm{CCyC}$ en los arts. 560 a 562. Nace la niña y se presenta al registro civil marplatense los tres consentimientos informados. ¿Sobre la base de qué variable, el registro civil puede escoger dos de los tres consentimientos firmados para cumplir con el principio binario que rige en material filial? Ante la oposición de inscribir a la niña bajo una triple filiación por parte del registro civil local como así también el central con sede en La Plata -contrariamente a lo que se había decidido en la gestión anterior- se acudió a la justicia. A la fecha en que se está redactando el presente ensayo, continúa el trámite judicial, advirtiéndose que la niña ya lleva más de un año con un sólo vínculo filial, el materno, y aún invisibilizados los otros dos lazos afectivos que en la práctica, son tan genuinos, sólidos y reales como el único vínculo jurídico reconocido hasta la actualidad.

De manera más reciente aún, el Juzgado de Familia nro. 4 de La Plata en fecha 20/02/2017 dictó la primera sentencia que admite la triple filiación de una niña de 11 de edad ${ }^{34}$. A diferencia de los restantes supuestos, no se trata de parejas del mismo sexo ni tampoco de técnicas de reproducción asistida o casera, sino que involucra un caso de adopción de integración en la que todos los protagonistas de esta historia (marido de la madre y pretenso adoptante, los progenitores y la propia niña), solicitan que dicha adopción mantenga intacto el vínculo filial con el progenitor no conviviente, es decir, que la adopción de integración simple no traslade el ejercicio de la responsabilidad parental del progenitor no conviviente al adoptante, sino que ambos, conjuntamente con la madre, ejerzan todos los actos que se derivan de la responsabilidad parental. Para ello, en el escrito de inicio de la petición de adopción se deja en claro que "No se pretende extinguir, sustituir o restringir vínculos, sino todo lo contrario, ampliarlos mediante la integración de un tercero que no fue primigeniamente parte de la familia". Tanto la fiscalía como la asesoría de menores prestaron conformidad sin advertir el planteo de triple filiación que encerraba el caso, al igual que la jueza interviniente que en la fecha mencionada hizo lugar a la adopción de integración "Creando entre estos el vínculo de filiación adoptiva de integración simple, con todos los efectos previstos por la ley respecto de dicha adopción", es decir, desoyéndose lo que todos los integrantes de la familia estaban solicitando. Ante este panorama, tanto el pretenso adoptante como el progenitor no conviviente presentan escritos solicitando se aclare los términos o efectos de la adopción

33 El art. 558 del CCyC en su última parte establece: "Ninguna persona puede tener más de dos vínculos filiales, cualquiera sea la naturaleza de la filiación."

34 Juzgado de Familia Nro. 4, La Plata, 20/02/2017, "B.A.J.M. s/adopción acciones vinculadas”, inédito. 
y es ahí cuando, tanto la jueza como la asesora de menores, advierten del pedido de reconocimiento de triple filiación. Ante esta circunstancia, la asesora de menores apela en abierta contradicción a la conformidad que había prestado durante todo el proceso, es decir, en contra de la conocida teoría de los actos propios- y por pedido de la fiscal de que tenga una audiencia con la niña y conozca en profundidad su situación afectivafamiliar, modifica su opinión y desiste del recurso de apelación. En este contexto, la jueza en auto ampliatorio de fecha 06/03/2017 dispone que "En virtud de lo peticionado, líbrese oficio al Registro Civil para que proceda a inmovilizar el acta de nacimiento original de la niña... y se proceda a confeccionar una nueva inscripción de nacimiento con los recaudos ... debiendo surgir inequívocamente del cuerpo del acto su triple filiación".

Este tipo de debates que movilizan cimientos estructurales de uno de los ámbitos más importantes o de mayor relevancia de las relaciones de familia como lo es el filial, se pueden dar en el marco de un ordenamiento jurídico que es uno de los más avanzados del globo, y ni qué decir de Latinoamérica. El derecho argentino ha dado grandes pasos legislativos en la materia y ello se debe o fue auspiciado por un determinado contexto político. ¿Acaso las leyes no las sanciona uno de los poderes del Estado, un organismo como el Legislativo que es eminentemente político y que representa la voluntad del pueblo que habla a través del voto?

¿Es posible retroceder varios casilleros en este juego político- legislativo? Ello depende de la fortaleza de los argumentos que sostienen todos los avances legislativos alcanzados y a la par, del grado de consolidación que habrían logrado. Más allá de ello, y como se ha visto con varios ejemplos concretos, tanto en reproducción asistida y la cuestión del embrión in vitro o de manera más reciente, con la incidencia del cambio de gobierno en la aceptación o rechazo de la triple filiación en la Provincia de Buenos Aires, son situaciones que a modo de alarma nos obligan a estar bien atentos en clave de avances y retrocesos jurídicos.

En definitiva, se trata de admitir y comprender de qué modo los acontecimientos políticos pueden colaborar o perjudicar u obstaculizar la conquista de más y mejores derechos. No por casualidad el Congreso de la Nación en la actualidad, podría ser catalogado del lugar en el que se observa con mayor tensión esta puja entre avances y retrocesos, no sólo en el plano legal en sí, sino lo que ello significa en términos de agenda pública.

\section{Breves palabras ácidas de cierre}

Con la misma intrepidez que decidí ser docente e investigadora del CONICET con una concepción y un rol muy diferente a la que se le suele atribuir a ambos perfiles en o desde el campo jurídico, he redactado este artículo crítico. Crítico en varios sentidos: de la realidad social imperante; del modo en que se enseña, transmite y problematiza el derecho; de la manera que se pretende salir de un lugar obligatoriamente "incómodo" al no aceptar que el derecho es político, que forma parte de las distintas herramientas de transformación cultural y lo peor de todo -o mejor, según el lugar desde donde se lo mire-, es que se trata de un instrumento de suma riqueza y profundidad. ¿Cómo habría 
colaborado el nuevo texto civil y comercial a desenmascarar estas tensiones que esconde el Derecho? ¿Será por ello que se lo ha criticado tanto para evitar cualquier intento "subversivo" de ampliación de derechos y a la par, de extender derechos a núcleos familiares sistemáticamente silenciados y excluidos? ¿Será que la sola idea de pensar en un derecho más "popular" lleva consigo, una conducta reactiva sin poder, al menos, tratar de comprender los debates y desafíos que están detrás?

Es justamente por todo ello y varios argumentos más que no se comparte la mirada temerosa ante "Las consecuencias jurídicas de la 'grieta' Argentina" que esgrime Ciuro Caldani $^{35}$, presumiéndose como punto de partida que dicha grieta es "tan perjudicial para nuestra sociedad" y, por lo tanto, "Con miras a superar la grieta es imprescindible saber en qué consiste y conocer sus consecuencias. En el panorama estratégico hay que atender a las fortalezas, que son propias, las oportunidades, que provienen del exterior, las debilidades, que son propias, y las amenazas del exterior. La grieta es una debilidad estratégica de gran significación. Nuestras fortalezas y nuestras oportunidades, que suelen ser muchas, son en gran medida neutralizadas por nuestra propia debilidad producida por el desacuerdo". Esta perspectiva encierra varios interrogantes que parten de una aseveración que debería ser puesta en tela de juicio. ¿Existe esa supuesta "grieta" como tal? Según el sociólogo Horacio González, la grieta "Es una fantasmagoría para asustar y es un enfoque falso de lo que es la sociedad", agregando que ese término sirve "para justificar que hay un mal, que en este caso lo enmarca en el gobierno de Cristina Fernández de Kirchner" y que "la grieta es una metáfora de los intelectuales de la televisión como Jorge Lanata o Luis Majul"36. Más allá de si existe o no, en el supuesto de que nos inclinemos por la afirmativa, también se deberían dejar esgrimidos otros interrogantes. ¿La mencionada grieta sería de por sí negativa, o podría ser vista como una oportunidad para ampliar los debates y los estudios un tanto -y erradamenteasépticos y, por lo tanto, limitados que primaron en el Derecho? ¿Acaso tales fortalezas y debilidades no podrían también ser indagadas en ambos márgenes de la grieta, lo cual implica mayor riqueza que pretender -de manera un tanto naif- que haya un solo surco con sus propias fortalezas y debilidades? En definitiva, cuál es el miedo y la resistencia a los desacuerdos y los choques o confrontaciones lógicas que se derivan de diferentes maneras de entender, encarar y actuar sobre la realidad social. Precisamente, el pensamiento crítico no sólo valora la grieta jurídica, sino que se propone profundizar en, desde y con ella como excelente disparador y oportunidad para un necesario replanteo del Derecho hoy, en particular, de las relaciones de familia contemporáneas.

Se trata de seguir interpelando lo dado, como si ello no fuera construido por, desde y para lo social. Como bien lo ha dicho Einstein: "El mundo no será destruido por las personas que hacen el mal. Sino por las que se sientan a ver lo que pasa"; o en palabras del recordado Rodolfo Walsh: "Un intelectual que no comprende lo que pasa en su tiempo

35 Ciuro Caldani, Miguel A., "Las consecuencias jurídicas de la "grieta” argentina”, La Ley 24/07/2017, 1 Cita Online: AR/DOC/1277/2017, p. 1 y ss.

36 "Horacio González distinguido por la Unmdp: “Dejé de ser docente por miedo a la CNU”, 0223, 04/07/2017, disponible en: http://www.0223.com.ar/nota/2017-6-4-11-28-0-horacio-gonzalez-distinguido-por-launmdp-deje-de-ser-docente-por-miedo-a-la-cnu, compulsada el 24/07/2017. 
y en su país es una contradicción andante; y el que comprendiendo no actúa, tendrá un lugar en la antología del llanto, no en la historia viva de su tierra”. Se trata de seguir estando, diciendo y haciendo de manera crítica en el que lo político sea interpelado como una faceta enriquecedora y obligada del Derecho. Sólo así se podrá no ser funcional a un sistema como el jurídico, en el que siempre ha primado lo dado por sobre lo complejo; lo jerárquico por sobre lo horizontal; lo individual por sobre lo colectivo; lo legal por sobre lo humano.

En definitiva, las relaciones jurídicas de familia son vínculos de poder intra y extra sociales y, por ende, no pueden ni deben ser estudiadas por fuera de la política. Algo tan elemental como aún resistido, de allí la razón de ser del presente ensayo. 
